\title{
Editorial: Methodological innovations in qualitative educational research
}

\section{A special feature for the London Review of Education

\author{
Charlotte Vidal-Hall, Nozomi Sakata* and Rob Higham - UCL Institute of \\ Education, UK
}

Methodological development and innovation in educational research have attracted recent scholarly attention. The National Centre for Research Methods identified a number of methodological challenges for the twenty-first century and highlighted e-research, participatory and creative methods as sites of potential innovation (Crow, 2013). In 2015-17 the British Educational Research Association organized a series of Presidential Round Table Seminars to explore key methodological challenges facing the education research community. These events reflected the complexities of researching diverse and often 'messy' educational settings. While methodological 'innovation' is a debated term - not least because new approaches tend to be adaptions rather than wholly new approaches - there is widespread interest in genuine attempts to improve different aspects of the research process, which may help to inform the agenda for future research (Wiles et al., 2011).

In this context, this special thematic section includes articles that report on new developments in qualitative educational research. As editors, we were interested in articles that developed new or adapted existing methodologies in response to identified challenges, including those relating to: researching new contexts, settings and spaces of education; using new conceptual insights to inform education research; and researching educational practices or actors that have previously been seen as 'difficult' to research. We were also particularly interested in articles that sought to explain the authors' methodological decision-making, so as to provide rich insights into the research challenges they faced, the considerations, dilemmas and events that led to their emergent research methodology and how this influenced their research findings.

The resulting four articles provide fascinating insights across a variety of themes. Adhikary and Lingard report on their approach to researching Teach for Bangladesh. Arguing that policy sociology has a tendency to understand globalizing policies within global networks, the authors demonstrate the need to unravel intersecting global and local networks of philanthropy, given the 'glocal' nature of Teach for Bangladesh. The resulting research encompassed a mixing of global and local network ethnographies. Adhikary and Lingard discuss the challenges of this approach, but also show how this enabled analysis of the spatialities of the global-local relations and resources that have constituted Teach for Bangladesh.

Culshaw reflects on her use of arts-based methods, which she argues is a sometimes under-theorized approach to conducting education research. Seeking to explore what 'struggling' means to teachers, Culshaw discusses the potential of collage as an approach to allowing participants to access and further articulate their feelings of difficult experiences. While discussing the analytical challenges faced, which included 
interrelating the visual data with teachers' interview accounts, Culshaw argues this approach enabled participants to explore and express themselves beyond the spoken word and, as a result, to develop a richer understanding of what 'struggling' means.

The emerging field of psychosocial studies within educational research is presented by Hogan. A secondary school teacher and clinical practitioner in psychodynamic analysis, Hogan's focus is on psychodynamic accounts of teaching practice. Hogan presents the methodological and analytical complexities of conducting psychosocial research in an ethical manner. Advocating for both co-authored and autoethnographic approaches, Hogan argues that analysing 'psychodynamic incidents' allows for the psychological and emotional elements of teaching to be authentically researched.

Martin, Burbach, Benitez and Ramiz report on their engagement of young people in vulnerable communities as co-researchers (and co-authors) in youth participatory action research. The co-researchers reflect on two projects: an educational intervention in a refugee camp in Kenya, and research with young people in an alternative high school in the United States. Comparing these two contexts, they demonstrate how their approach to identifying, hearing and valuing the voices of these underrepresented communities enables the development of 'counter-narratives' to existing policies. These critical narratives summarize how the experiences and knowledges of young people can help to make local change more meaningful and relevant to them.

\section{Notes on the editors}

Charlotte Vidal-Hall recently completed a PhD at the UCL Institute of Education and works part time as a researcher for Ofsted. She has a long-standing interest in digital technology and effective pedagogy to support its integration in early years classrooms. Her doctoral research used a design-based approach to investigate early years teacher beliefs and implement change in practice around the use of digital media. She was an early years and primary teacher for 15 years.

Nozomi Sakata is Postdoctoral Researcher at UCL Institute of Education. She completed her PhD in Education and International Development in 2019, looking at the implementation of learner-centred pedagogy in Tanzanian primary schools from pupils' perspectives. Her research interests include educational policy diffusion and implementation with a focus on pedagogical reform in developing countries, and the use of mixed methods in international and comparative education.

Rob Higham is Associate Professor at UCL Institute of Education. His research explores the organization of state schools, the operation of markets in schooling and the involvement of civil society groups and businesses in the opening and governing of schools. As well as research on free schools, Rob has recently explored how schools in England have interpreted and begun to respond to the raft of policy reforms introduced in England from 2010, including in the public report: 'Hierarchy, Markets and Networks: Analysing the "self-improving school-led system" agenda in England and the implications for schools'.

\section{Articles in this London Review of Education feature}

Adhikary, R.W. and Lingard, B. (2019) 'Global-local imbrications in education policy: Methodological reflections on researching the sociology of Teach for Bangladesh'. London Review of Education, 17 (3), 252-67. 
Culshaw, S. (2019) 'The unspoken power of collage? Using an innovative arts-based research method to explore the experience of struggling as a teacher'. London Review of Education, 17 (3), 268-83.

Hogan, A. (2019) 'Psychodynamic incidents in teaching: Researching psychodynamic aspects of classroom practice'. London Review of Education, 17 (3), 284-96.

Martin, S.B., Burbach, J.H., Benitez, L.L. and Ramiz, I. (2019) 'Reflections on co-researching: A tool for bringing youth knowledge to the centre of research'. London Review of Education, 17 (3), 297-313.

\section{References}

Crow, G. (2013) 'Methodological challenges for the 21st century'. Presentation at the National Centre for Research Methods (NCRM) Autumn School for Early Career Researchers, Southampton, 6-8 November 2013. Online. https://tinyurl.com/y4nomfu3 (accessed 7 August 2019).

Wiles, R., Crow, G. and Pain, H. (2011) 'Innovation in qualitative research methods: A narrative review'. Qualitative Research, 11 (5), 587-604. 